\title{
Inventário de Dicksonia sellowiana Hook. em Santa Catarina
}

André Luís de Gasper ${ }^{1,4}$, Lucia Sevegnani ${ }^{1}$, Alexander Christian Vibrans ${ }^{2}$, Alexandre Uhlmann ${ }^{3}$, Débora Vanessa Lingner ${ }^{2}$, Marcio Verdi², Susana Dreveck², Anita Stival-Santos ${ }^{2}$, Eduardo Brogni², Ronnie Schmitt ${ }^{2}$ e Guilherme Klemz ${ }^{2}$

Recebido em 13/07/2010. Aceito em 22/08/2011

\section{RESUMO}

(Inventário de Dicksonia sellowiana Hook. em Santa Catarina). A intensa exploração comercial de Dicksonia sellowiana a deixaram na categoria de ameaçada de extinção, sendo incluída na lista brasileira de espécies da flora ameaçada de extinção. Por isso, o presente trabalho visa apresentar o estudo da distribuição das populações de D. sellowiana para apontar os locais de maior ocorrência da espécie em Santa Catarina, e avaliar a relação da densidade populacional com fatores ambientais, como altitude e clima. Foram instaladas 225 unidades amostrais, com $4.000 \mathrm{~m}^{2}$ nas regiões do planalto e oeste catarinense, baseadas na grade de $10 \mathrm{~km} \mathrm{x} 10 \mathrm{~km}$ conforme procedimento do Inventário Florístico Florestal de Santa Catarina. Nestas 225 unidades amostrais, D. sellowiana foi encontrada em 94, com variação de um a 391 indivíduos. A grande densidade da espécie em áreas mais elevadas (superiores a $1.000 \mathrm{~m}$ ) está relacionada com os dados climáticos que influenciam a população diretamente, apontados pelo Critério de Informação de Akaike corrigido, ou seja, a altitude e a variação de temperatura que ela provoca. Observou-se também, que a espécie apresenta maior concentração da população nos menores intervalos de altura e diâmetro, chegando a elevadas densidades com até 977 indivíduos/ha em algumas áreas. As informações obtidas pelo inventário sobre esta espécie possibilitam indicar medidas de conservação para a espécie, como área a serem conservadas e apoio a produtores rurais.

Palavras-chave: Floresta Ombrófila Mista, Dicksoniaceae, xaxim-bugio, distribuição geográfica, estrutura populacional, ameaça de extinção

\begin{abstract}
(Inventory of Dicksonia sellowiana Hook. in Santa Catarina). The intense exploitation of Dicksonia sellowiana has led this species to become endangered and to be included on the red list of threatened species. Therefore, this paper presents a study of D. sellowiana populations in Santa Catarina State, and points out the places where it occurs the most, the status of these populations and also evaluates the relationship between density, climatic variables and elevation. Two hundred and twenty-five sample plots, which were $4.000 \mathrm{~m}^{2}$ each, were located within the study area and based on a $10 \times 10 \mathrm{~km}$ grid according to procedures of the Forest and Floristic Inventory of Santa Catarina. Dicksonia sellowiana was found in 94 of these plots, where it ranged from 1 to 391 individuals. The density of the species at higher elevations (above $1.000 \mathrm{~m}$ ) seemed to be related to climatic data that directly influences the populations, as pointed out by the corrected Akaike Information Criterion (AICc). This study also found that the species populations exhibit high densities in the lower height and diameter ranges, reaching values up to 977 individuals/ha in some stands. The information obtained during this study makes it possible to suggest conservation measures for this species, such as areas to be conserved in a way that supports small farms
\end{abstract}

Key words: Mixed Ombrofilous Forest, Dicksoniaceae, xaxim-bugio, geographical distribution, population structure, endangered species

\footnotetext{
1 Universidade Regional de Blumenau, Herbário Dr. Roberto Miguel Klein, Blumenau, SC, Brasil

2 Universidade Regional de Blumenau, Departamento de Engenharia Florestal, Blumenau, SC, Brasil

3 Embrapa Florestas, Colombo, PR, Brasil

4 Autor para correspondência algasper@gmail.com
} 


\section{Introdução}

No Brasil, o estudo das pteridófitas muitas vezes resumese à florística (Senna \& Kazmirczak 1997; Salino \& Almeida 2008; Athayde Filho \& Felizardo 2010) e à taxonomia (Sehenm 1978, Rolim \& Salino 2008; Assis \& Salino 2010), sendo pouco expressiva a pesquisa ecológica deste grupo (Arens \& Baracaldo 1998; Bittencourt et al. 2004; Franz \& Schmitt 2005; Dittrich et al. 2005; Santos \& Sylvestre 2006), bem como aquela que aborde aspectos da distribuição espacial e as relações com o clima (Tuomisto \& Poulsen 2000; Tuomisto et al. 2002; Jones et al. 2006)

Alguns trabalhos que tratam da estrutura populacional de samambaias arborescentes têm sido realizados recentemente no Sul do Brasil, tais como os de Schmitt \& Windisch (2005, 2007), Sampaio \& Guarino (2007) e Schmitt et al. (2009) que abordam a estrutura populacional e alguns aspectos ecológicos e reprodutivos. O estudo apresentado por Mantovani (2004) sobre Dicksonia sellowiana possibilitou o conhecimento da estrutura fitossociológicas e dos ambientes onde esta espécie se insere, bem como, das exigências climáticas e edáficas para sua ocorrência em Santa Catarina. A espécie é comumente listada em trabalhos fitossociológicos no Sul do país, com grande valor de importância nas comunidades estudadas (Sanquetta et al. 2007; Gomes et al. 2008; Biondi et al. 2009).

Dicksonia sellowiana é uma espécie de fácil reconhecimento e apresenta-se como uma das mais características da vegetação nas regiões do planalto e oeste catarinense. Possui porte arbóreo-arbustivo (fetos arborescentes), seu cáudice, engrossado pela densa trama de raízes adventícias e frondes muitas vezes maiores que um metro de comprimento. Seus cáudices eram usados para produção de vasos, e sua intensa exploração no final do século XX levou a espécie a ser incluída na lista brasileira de espécies da flora ameaçadas de extinção (Windisch 2002; MMA 2008; Pillar et al. 2009).

Trata-se de uma espécie de grande importância ecológica (Senna 1996), não apenas pela grande quantidade de matéria orgânica que pode adicionar ao solo, mas também por abrigar muitas espécies de epífitas, algumas de forma exclusiva (Sehnem 1978; Cortez 2001; Fraga et al. 2008). Ocorre desde o sul do México, até o sul do Brasil (Tryon \& Tryon 1982), crescendo em altitudes que variam de 60 até $2.200 \mathrm{~m}$ (Fernandes 1997). É frequente em muitas florestas de Santa Catarina, sendo comumente encontrada no Planalto Sul-Brasileiro em áreas cobertas por Floresta Ombrófila Mista.

No ano de 2005, instituições de pesquisa de Santa Catarina iniciaram o Inventário Florístico Florestal de Santa Catarina (IFFSC) objetivando: a) conhecer a quantidade e a qualidade das florestas ainda existente no Estado; b) determinar o seu estado de conservação ou degradação; c) avaliar a distribuição espacial e o potencial das diversas espécies de árvores, inclusive das raras e ameaçadas de extinção, para fundamentar políticas de uso do solo e de conservação dos recursos naturais. Depois de concluída a etapa de levantamentos em campo, relevante conjunto de informações foi gerado, sendo que as relativas à $D$. sellowiana serão exploradas no presente trabalho.

Diante da importância econômica e ecológica de $D$. sellowiana, o presente trabalho objetiva avaliar a estrutura populacional desta espécie, bem como fatores ambientais condicionantes no âmbito das Florestas Ombrófila Mista e Estacional Decidual, em Santa Catarina, visando propor medidas de conservação in situ.

\section{Material e métodos}

A área abrangida neste estudo compreende o Planalto e o Oeste do estado de Santa Catariana, que constituem as Regiões Fitoecológicas da Floresta Ombrófila Mista e da Floresta Estacional Decidual (Veloso et al. 1991), localizadas principalmente na bacia do rio Uruguai e em pequena parte na do rio Iguaçu. O planalto norte está assentado sobre rochas sedimentares do paleozóico e o segmento da área de estudo que se situa para oeste da escarpa da Serra Geral, está sobre as eruptivas mesozóicas, o que condiciona a origem de diferentes tipos de solos (Maack 1968).

O que denominamos de Planalto, segundo a classificação de Köppen, apresenta clima mesotérmico úmido com verão fresco (Cfb), em altitudes superiores a $800 \mathrm{~m}$ (Nimer 1989). As temperaturas médias anuais oscilam entre 13,4 e 16,5 ${ }^{\circ} \mathrm{C}$. O regime de chuvas é bastante regular no território, com índices pluviométricos superiores a $1.300 \mathrm{~mm}$ anuais, sendo que na porção sul do Planalto, os registros de precipitação média anual estão compreendidos entre 1.370 a $1.992 \mathrm{~mm}$ (Santa Catarina 2007), ainda com ocorrência de geadas e de neve. Já o Oeste apresenta clima mesotérmico úmido de verão quente (Cfa), com temperaturas médias anuais oscilando entre 18,3 e $19,4{ }^{\circ} \mathrm{C}$, com índices pluviométricos superiores a $2.000 \mathrm{~mm}$ anuais.

Os pontos potenciais para amostragem foram distribuídos sistematicamente ao longo de uma grade de 10 x 10 $\mathrm{km}$ distribuídos pela área amostrada (vide Vibrans et al. 2010), conformando uma grade sobreposta ao mapa dos remanescentes florestais de Santa Catarina (Fig. 1). As áreas com floresta natural foram extraídas do mapa de uso do solo elaborado pela Secretaria de Agricultura e Abastecimento do Estado de Santa Catarina (SAR 2005). Este mapeamento foi realizado com base na interpretação visual de imagens orbitais dos satélites Landsat-5 TM e Landsat-7 ETM+ de 2003 e 2004. As regiões fitoecológicas seguem o mapeamento efetuado por Klein (1978).

Os pontos da grade que coincidiram com um remanescente de floresta natural de superfície maior que 10 ha, foram considerados amostráveis e, no campo, instalou-se uma unidade amostral (UA) composta por um conglomerado básico com $4.000 \mathrm{~m}^{2}$, com tolerância de deslocamento de $250 \mathrm{~m}$ do ponto amostral, caso não houvesse vegetação florestal no ponto indicado pela grade, visando melhor 


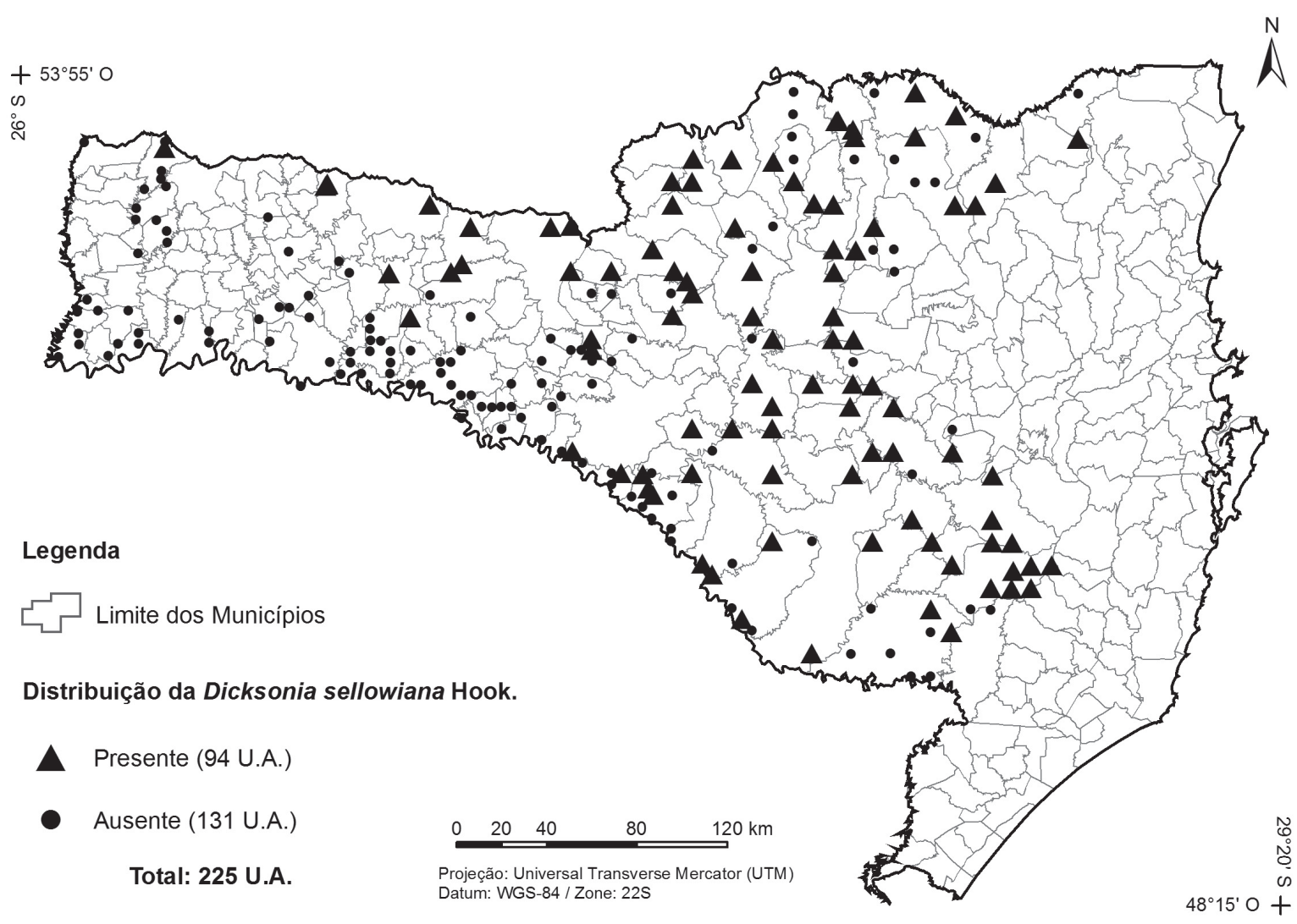

Figura 1. Localização das Unidades Amostrais instaladas no planalto e oeste do estado de Santa Catarina.

enquadrar a Unidade Amostral no fragmento. O conglomerado foi constituído por quatro subunidades, com área de $1.000 \mathrm{~m}^{2}$ cada uma, medindo $20 \mathrm{~m} \times 50 \mathrm{~m}$ de comprimento, orientadas na direção norte, sul, leste e oeste (Fig. 2). Em cada UA foram registradas as coordenadas geográficas e a altitude, demarcando-se o seu centro com uma estaca de ferro (Vibrans et al. 2010).

Dos indivíduos do componente arbóreo com diâmetro à altura do peito (DAP) igual ou maior do que $10 \mathrm{~cm}$, a 1,3 $\mathrm{m}$ do solo, presentes no interior das UA's, foram medidos o diâmetro e a altura total, as ramificações também foram consideradas para análise. De cada fragmento e UA foi efetuada a descrição detalhada da fisionomia, do estado de conservação e dos fatores de degradação antrópica internos e do entorno.

A descrição da fisionomia da vegetação foi feita com base em: altura e fechamento do dossel, número de sinúsias presentes e principais componentes da sinúsia arbórea e arbustiva. O estado de conservação foi obtido de modo indireto, a partir da avaliação visual da qualidade estrutural da vegetação, tomando por base as descrições feitas por Klein (1978) - estas consideradas como o estado de qualidade para cada uma das regiões fitoecológicas de SC, além de verificar a ausência ou presença dos fatores de degradação, e com base nos parâmetro do CONAMA (1994). A constatação dos fatores de degradação internos a unidade amostral e externos ao fragmento foi feita através observação da presença ou ausência de ações humanas perturbadoras da floresta, citando-os e descrevendo sucintamente os impactos negativos constatados.

Para a caracterização da estrutura populacional, os indivíduos foram separados em intervalos de tamanho, adotando como critério de inclusão a altura mínima de $1,5 \mathrm{~m}$, conforme definido em Vibrans et al. (2010), para o projeto IFFSC. Os intervalos de altura adotados foram de $50 \mathrm{~cm}$, a partir de 1,5 m, com intervalos fechados à esquerda. Além de intervalos de altura, intervalos de diâmetro foram de 5 $\mathrm{cm}$, a partir de $10 \mathrm{~cm}$, com intervalos fechados à esquerda.

Dentre todas as UAs consideradas na área de estudo, foram selecionadas aquelas nas quais $D$. sellowiana estava presente. Para estas UAs, foram calculados os parâmetros fitossociológicos: densidade, dominância (a partir da área basal), frequência (Mueller-Dombois \& Ellenberg 1974), mediana das alturas mediana e índice de diversidade de Shannon (Margurran 1988). A análise dos dados foi feita através dos softwares Statistica 8 (StatSoft Inc., 2007), BIOSTAT 5.0 (Ayres et al. 2007) e Mata Nativa $2^{\odot}$ (CIENTEC 2002).

Para a análise de regressão múltipla, uma variável sintética RIV (baseada em Oliveira-Filho et al. 1998) foi utilizada como variável resposta. Esta variável sintética tem como objetivo relativizar as populações adultas com área basal 


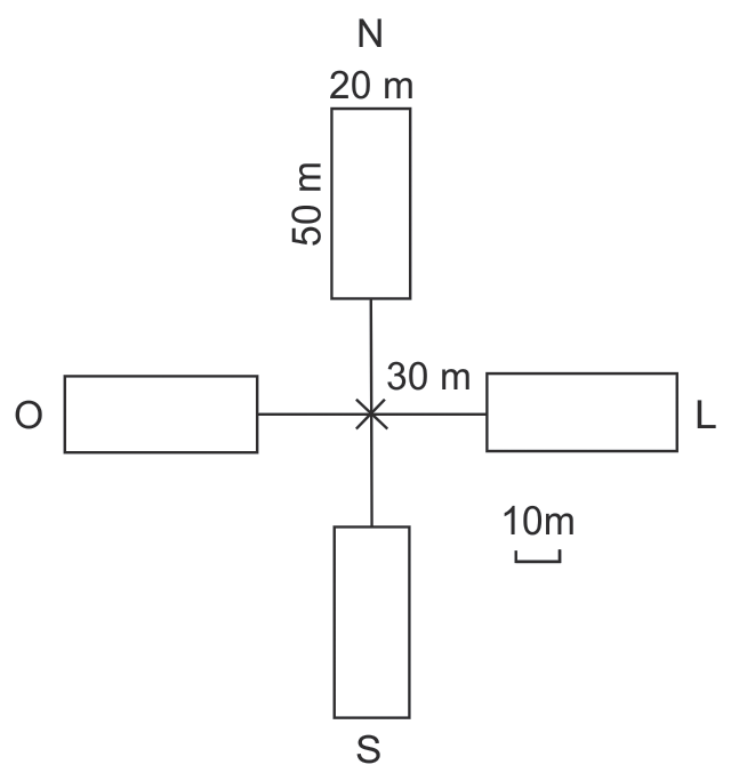

Figura 2. Configuração espacial do conglomerado implantado nas unidades amostrais do Inventário Florístico Florestal de Santa Catarina, Brasil.

elevada e as populações jovens, com muitos indivíduos, mas baixa área basal. Esta variável foi testada através da seleção do melhor modelo com base no menor Critério de Informação de Akaike corrigido (Burnham \& Anderson 2002) para verificar quais variáveis climáticas e abióticas influenciavam mais fortemente a variação da densidade de D. sellowiana. As seguintes variáveis foram examinadas: altitude, dias de geada, precipitação, temperatura máxima, mínima e média, umidade, insolação e evapotranspiração. Essas foram extraídas do Atlas Climatológico de Santa Catarina (Epagri 2008). A avaliação de multicolinearidade foi aplicada no software SAM v4.0 (Rangel et al. 2010).

Após a remoção de variáveis multicolineares (isto é, com Fator de Inflação da Variância acima de 10, conforme Seaby \& Henderson (2007), o modelo passou a incluir somente as variáveis altitude, precipitação, temperatura mínima, umidade, insolação e evapotranspiração. Deste conjunto de variáveis, foi feita a seleção do melhor modelo com base no menor Critério de Informação de Akaike corrigido.

\section{Resultados e discussão}

Das 225 unidades amostrais (UA) inventariadas, $D$. sellowiana foi encontrada em 94 (42\%) somando 37,03 ha mensurados. O total de indivíduos amostrados de D. sellowiana foi de 5.786, sendo que 328 apresentavam de uma a seis ramificações (totalizando 415 ramificações). De acordo com as descrições de campo, 51 das UA medidas foram classificadas como primárias, 41 secundárias em estádio avançado de regeneração e duas secundárias em estádio médio de regeneração.

O número médio estimado de $D$. sellowiana foi de 61 indivíduos/UA, com valores variando entre um (12 UA) e
391 indivíduos (uma UA). O DAP oscilou entre 10 e $77 \mathrm{~cm}$, com média de $67,5 \mathrm{~cm}$. A mediana das alturas da amostra foi de $3 \mathrm{~m}(Q 12,3 ; \mathrm{Q} 3$ 3,5; IQR 1,2). A estimativa da densidade absoluta resultou em 156 indivíduos ha-1 e a de dominância absoluta em 7,6 $\mathrm{m}^{2} \mathrm{ha}^{-1}$ (Tab. 1). Com relação aos dados fitossociológicos, D. sellowiana apresentou o valor de importância (VI) mais elevado $(51,5)$, suplantando as demais espécies entre elas Araucaria angustifolia $(14,3)$, que ficou em segundo lugar.

A distribuição espacial foi determinada como agregada, como pode ser constatada em campo quando UA's apresentavam elevada densidade de indivíduos, chegando a formar florestas monodominantes, conforme o conceito de Connell \& Lowman (1989) e Hart et al. (1989). Muitos indivíduos acabavam caindo sobre o indivíduo lateral e formavam densas aglomerações, onde era impossível determinar se eram brotações do mesmo, ou a junção dos cáudices.

A maior concentração de indivíduos foi encontrada nos primeiros intervalos de altura (fig. 5a) e nos segundo e terceiro intervalor de diâmetro (fig. 5b). Juntos, os intervalos de altura 1 e 2, ou seja, até 3,5 m, somam 76\% dos indivíduos medidos, valores estes similares aos de outros trabalhos com fetos arborescentes (Schmitt \& Windisch 2005, 2007; Lehn \& Rezende 2007). O DAP médio também aumentou conforme o intervalo de altura, com exceção do último intervalo.

Já os intervalos de diâmetro entre 15 e 25 cm (2 e 3), concentraram quase $70 \%$ dos indivíduos. Esta elevada concentração também foi observada para Cyathea delgaddi Sternb. e Alsophila setosa Kaulf. (Schmitt \& Windisch 2005, 2007), assim como a baixa representatividade nos demais intervalos. Mesmo assim, há elevadas densidades nos intervalos 4 e 5, o que mostra algumas populações bem desenvolvidas.

Nas 10 UAs com maior abundância, foram encontrados 2.934 indivíduos $(50,5 \%)$ do total amostrado, indicando a elevada densidade que a espécie apresenta em algumas áreas. Estas 10 UA distribuem-se geograficamente da seguinte maneira: UA 192 (Urubici, altitude de 1.482 $\mathrm{m}$, três fatores de degradação e 391 indivíduos), UA 167 (Urubici, $1.139 \mathrm{mnm}$, dois fatores de degradação e 254 indivíduos), UA 165 (Urubici, $1.407 \mathrm{mnm}$, quatro fatores de degradação e 220 indivíduos) e 214 (Rio Rufino, 1.432 mnm, três fatores de degradação e 369 indivíduos). Todas foram consideradas como cobertas por vegetação primária, segundo o critério da área basal (Resolução CONAMA 04/1994), e enquadradas como Floresta Ombrófila Mista Altomontana, algumas em transição com Floresta Ombrófila Mista, Estepe ou campos naturais, vizinhas umas às outras, sendo algumas localizadas no Parque Nacional de São Joaquim ou em Parques Municipais, mas outras tantas em propriedades particulares, sem garantias de preservação. Dentre os fatores de degradação observados nos fragmentos estudados, o corte seletivo, o corte raso (histórico e atual) e a presença de estradas e roçadas foram os mais frequentes (Tab. 2). 
Tabela 1. Variáveis observadas para a espécie Dicksonia sellowiana (A), para toda a comunidade nas 94 unidades amostrais onde a espécie está presente (B), e nas demais 225 inventariadas (C) no planalto e oeste de Santa Catarina, sul do Brasil.

\begin{tabular}{lccc}
\hline Variáveis & $\mathrm{A}$ & $\mathrm{B}^{*}$ & $\mathrm{C}$ \\
\hline Indivíduos & 5.786 & 24.038 & 48.133 \\
Área basal m $^{2}$ & 280,7 & $1.139,3$ & $2.212,63$ \\
Densidade absoluta (indivíduos $\left./ \mathrm{ha}^{-1}\right)$ & 156,2 & 648,9 & 563,88 \\
Dominância absoluta $\left(\mathrm{m}^{2} / \mathrm{ha}\right)$ & 7,6 & 30,79 & 300 \\
Valor de importância & 51,5 & 300 & 300 \\
Percentual de importância (\%) & 17,16 & 100 & 100 \\
\hline
\end{tabular}

*Demais espécies, sem $D$. sellowiana.

Tabela 2. Fatores de influências antrópicas no interior das 94 UA’s avaliadas onde Dicksonia sellowiana estava presente, no planalto e oeste de Santa Catarina, sul do Brasil.

\begin{tabular}{lcc}
\hline Influência & No de U.A. & $\%$ \\
\hline Roçada & 14 & 14,89 \\
Corte Seletivo & 64 & 68,09 \\
Corte Raso & 18 & 19,15 \\
Erva-mate & 8 & 8,51 \\
Pastejo & 53 & 56,38 \\
Caça & 6 & 6,38 \\
Espécie Exótica & 4 & 4,26 \\
Estradas & 28 & 29,79 \\
Fogueira & 2 & 2,13 \\
\hline
\end{tabular}

Dentre as cinco UA com maior abundância de indivíduos (variando entre 271 e 391 indivíduos), três estavam situadas na Floresta Ombrófila Mista Montana, em altitudes entre $1.070 \mathrm{~m}$ e $1.231 \mathrm{~m}$, e duas, na Floresta Ombrófila Mista Altomontana, em altitudes entre $1.432 \mathrm{~m}$ e $1.482 \mathrm{~m}$, todas consideradas como vegetação em estádio primário, segundo a legislação brasileira (Resolução CONAMA 04/1994).

Para uma melhor visualização da densidade da espécie no Estado, este foi dividido em quadrículas de 20 x $20 \mathrm{~km}$ (Fig. 3) com suas respectivas densidades. É possível observar uma grande densidade de indivíduos na região de Urubici e Santa Cecília, além de uma faixa de ocorrência na divisa com o Paraná (Serra do Espigão), áreas estas de grande altitude, como observado no mapa altimétrico de Santa Catarina (Fig. 4). As UAs amostradas situaram-se em locais com altitude mínima de 560 e máxima de $1.546 \mathrm{~m}$.

Segundo Mantovani (2004), D. sellowiana ocorre em altas densidades associada a um ambiente específico de interior de áreas florestadas, como se pode observar na fig. 3 , onde as maiores concentrações encontram-se nas encostas serranas, fato também observado por Sehnem (1978).

Através do modelo de AICc (-389.463), a altitude e a consequente variação da temperatura (que apresentaram o valor de $\mathrm{P}<0,001, \mathrm{r}^{2}: 0,367$ no melhor modelo), constituem dois preditores da variação da densidade da espécie, confirmando o observado nos mapas e na seleção das 10
UA’s com maior número de indivíduos. Nas maiores altitudes, a temperatura média é menor, bem como as mínimas absolutas registradas. Os resíduos foram testados por meio de correlogramas I de Moran (Legendre \& Fortin 1989; Diniz-Filho et al. 2003), nos quais não se observou estrutura espacial significativa com base na correção sequencial de Bonferroni (Fortin \& Dale 2005).

Pelos registros paleopalinológicos, desde o Holoceno Superior D. sellowiana aparece associada à Floresta Ombrófila Mista, inicialmente, ocupando as matas de galeria (Behling et al. 2004; Pillar et al. 2009). Ainda de acordo com os mesmos autores, a expansão da Floresta Ombrófila Mista e, supõe-se também, a de D. sellowiana, deve estar relacionada ao clima mais úmido, proporcionado por altas taxas pluviométricas e curtos períodos de seca.

Em um estudo com pteridófitas na Amazônia (Tuomisto \& Poulsen 2000), a densidade de indivíduos não foi afetada pela posição topográfica, muito provavelmente pela drenagem do solo. Em outro estudo, Tuomisto et al. (2002) estudaram pteridófitas e Melastomataceae e observaram uma clara correlação negativa entre as bases extraíveis do solo e o número de indivíduos encontrados em uma transecção. Neste trabalho, através das observações de campo, constatou-se que encostas, como as existentes no Parque Nacional de São Joaquim em Urubici e planaltos, como em Santa Cecília, eram dominadas por D. sellowiana, podendo diversos fatores, além de clima, solo e posição fisiográfica, atuar sinergeticamente e influenciar a elevada densidade desta espécie, como apontado por Mantovani (2004).

As áreas localizadas nas escarpas da Serra Geral são sempre muito úmidas, pela ação das massas de ar vindas do oceano, que formam nevoeiros e chuvas orográficas frequentes, mantendo as florestas fortemente hidratadas (Leite \& Klein 1990). O próprio cáudice da espécie favorece o acúmulo de água e a rápida absorção, além da mesma ser necessária para completar o ciclo de vida (Page 2002). Em um levantamento sobre a distribuição de fetos arborescentes ao longo de um mosaico sucessional na Colômbia, Arens \& Baracaldo (1998) observaram que em pastagens abandonadas há cerca de 20 anos, ocorria elevada densidade de D. sellowiana, o que não foi observado nas áreas de estudo, já que as áreas com elevada densidade apresentavam estrutura de uma floresta 


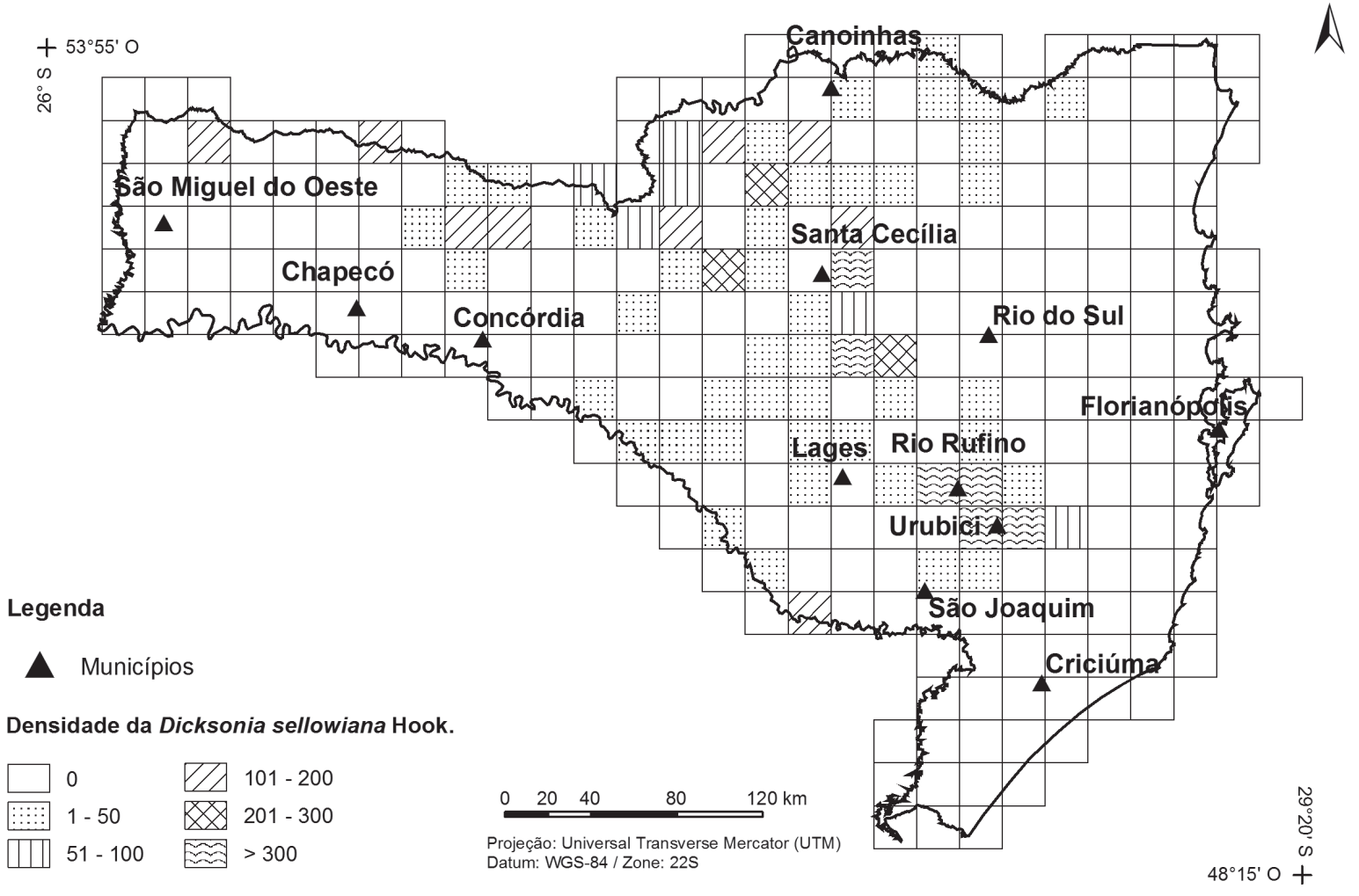

Figura 3. Densidade de Dicksonia sellowiana em quadrículas de 20 x 20 km amostradas no Inventário Florístico Florestal do Estado de Santa Catarina (IFFSC).

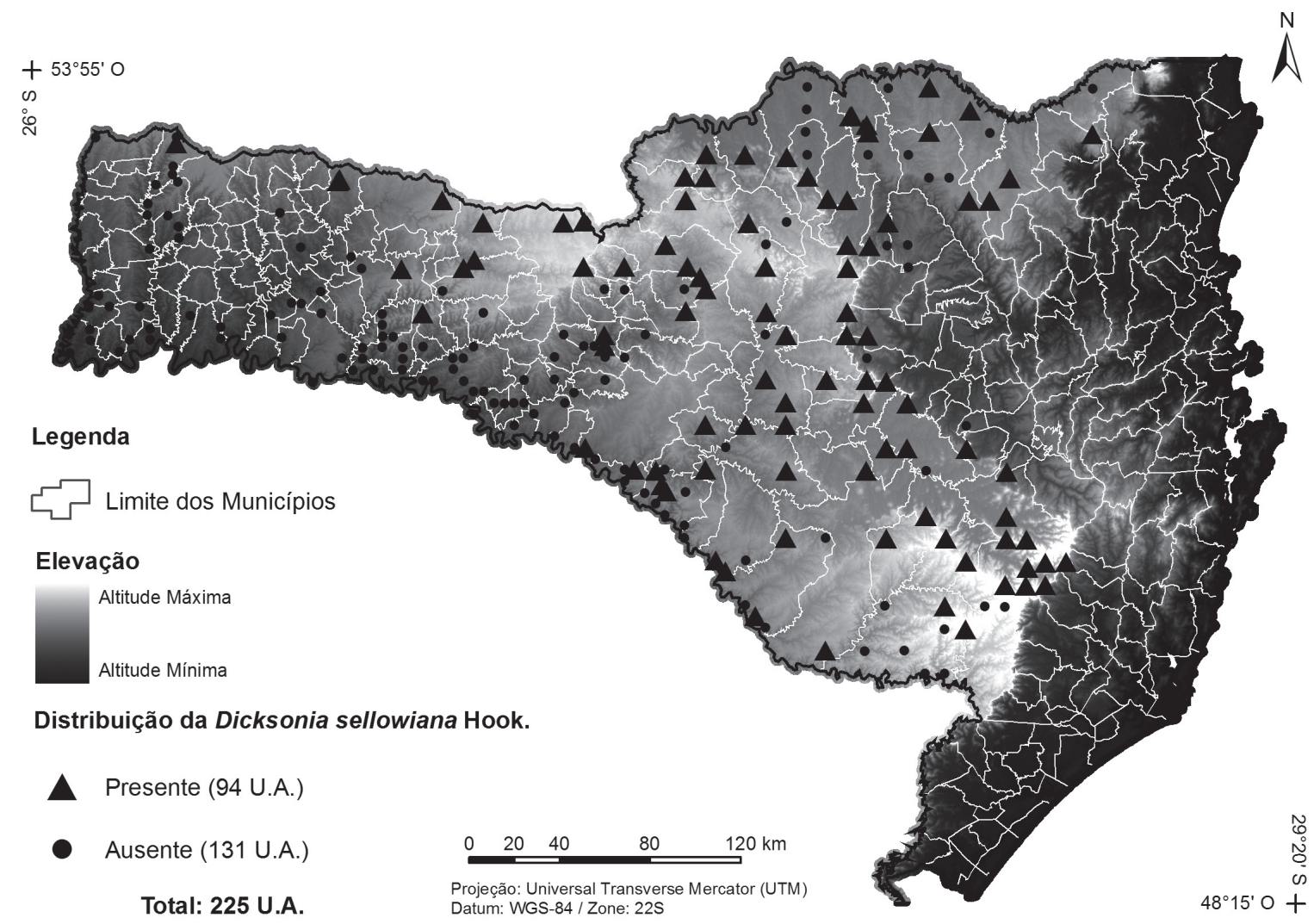

Figura 4. Distribuição dos pontos amostrais em Santa Catarina projetados sobre o mapa de altitude. 

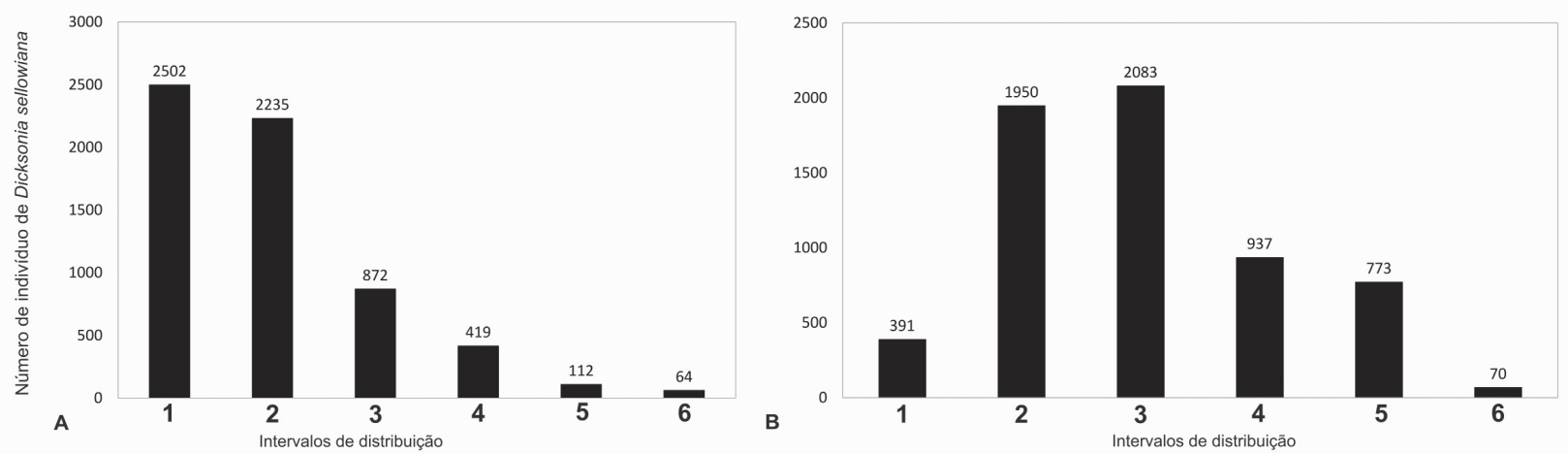

Figura 5. A: Intervalos de altura (a) e diâmetro (b) dos indivíduos de D. sellowiana na área amostrada.

muito mais antiga. Em áreas primárias e secundárias, estes mesmos autores, verificaram a ocorrência média de 140 a 240 indivíduos/ha, respectivamente, enquanto que nas áreas abertas, onde indivíduos desta espécie formavam o dossel, a densidade chegou a 3.200 indivíduos/ha. Neste trabalho, na UA192 (Urubici), a densidade chegou a 977 indivíduos/ ha, área esta situada a $1480 \mathrm{~m}$ de altitude e sob solo hidromórfico. Estes fatores podem ter contribuído para a elevada densidade da espécie neste local (mesmo considerada a sua exploração no passado).

Dicksonia sellowiana, em muitas áreas de Santa Catarina, aparece com baixa densidade devido à histórica exploração, em vista do elevado valor comercial que a espécie apresentou no mercado de plantas ornamentais, principalmente para a confecção de vasos, a partir de seus cáudices (Fernandes 2000; Windisch 2002). Segundo relatos colhidos nos trabalhos de campo, às vezes o corte de espécies ameaçadas de extinção é efetuado porque os proprietários de áreas com florestas percebem a presença das espécies protegidas por lei como empecilho à obtenção de autorizações para manejo do solo ou da floresta, junto aos órgãos ambientais.

Como dominante nas áreas de ocorrência, esta espécie é de grande importância para a manutenção da biodiversidade de epífitos, como apontaram Fraga et al. (2008). Estes autores observaram que, em uma área de Floresta Ombrófila Mista, D. sellowiana chegou a ser forófito para $67 \%$ das espécies epífitas de pteridófitas. Segundo Cortez (2001), tanto D. sellowiana quanto outras espécies de fetos arborescentes, constituem-se em substrato para o desenvolvimento de espécies que crescem exclusivamente sobre elas, e a extinção local destas pode levar a extinção de outras espécies a elas associadas.

De todas as UAs localizadas no âmbito da Floresta Estacional Decidual, em somente uma delas foi amostrado um indivíduo de D. sellowiana. Todas as demais UAs nas quais a espécie foi amostrada foram classificadas como pertencentes à unidade fitoecológica da Floresta Ombrófila Mista, ou seus ecótonos com a Floresta Ombrófila Densa e a Floresta Estacional Decidual, mostrando a preferência da mesma pela unidade fitoecológica, essa apresentando temperaturas inferiores e maiores altitudes o que corrobora com os dados climáticos e geográficos.

Apesar da grande densidade da espécie nas regiões mais elevadas, ambiente preferencial da espécie, faz-se necessária intensa fiscalização para coibir o corte ilegal da mesma, pois a exploração de D. sellowiana ainda ocorre em Santa Catarina. Unidades de conservação como o Parque Nacional de São Joaquim contribuem para a manutenção da espécie, mas é preciso ir além, gerando políticas de incentivo aos pequenos proprietários rurais, para que estes mantenham os ecossistemas e as espécies ameaçadas, seja nas APP’s (Áreas de Proteção Permanente) ou nas reservas legais das propriedades.

A possibilidade de manutenção da diversidade genética e de populações representativas de D. sellowiana depende de políticas públicas visando a sua proteção e fiscalização, aliados a efetivos programas de educação ambiental, além de mecanismos de incentivo aos proprietários, como o pagamento por serviços ecossistêmicos em toda a sua área de ocorrência em Santa Catarina.

\section{Agradecimentos}

Os autores agradecem a prestimosa colaboração na leitura e sugestão de análise a M.Sc. Pedro Eisenlohr e Dr. Ary Oliveira-Filho. Agradecem ainda à FAPESC pelo financiamento do projeto Inventário Florístico Florestal de Santa Catarina, à Universidade Regional de Blumenau e ao Herbário Dr. Roberto Miguel Klein (FURB).

\section{Referências bibliográficas}

Arens, N.C. \& Baracaldo, P.S. 1998. Distribution of tree ferns (Cyatheaceae) across a sucessional mosaic in an Andean cloud forest, Nariño, Colombia. American Fern Journal 88: 60-71.

Assis, F.C. \& Salino, A. 2010. Dennstaedtiaceae (Polypodiopsida) no estado de Minas Gerais, Brasil. Rodriguésia 62(1): 11-33.

Athayde Filho, F.P. \& Felizardo, M.P.P. 2010. Análise florística e ecológica das samambaias e licófitas da principal nascente do Rio Pindaíba, Mato Grosso. Pesquisas, Botânica 61: 229-244. 
Ayres M.; Ayre M.J.; Ayres D.L. \& Santos A.A.S. 2007. Bioestat: aplicações estatísticas nas áreas das ciências biomédicas (5.0). http://www. mamiraua.org.br/download. (Acesso em 05/05/2009).

Behling, H.; Pillar, V.D.; Orlóci, L. \& Bauermann, S.G. 2004. Late Quaternary Araucaria forest, grassland (Campos), fire and climate dynamics, studied by high-resolution pollen, charcoal and multivariate analysis of the Cambará do Sul core in southern Brazil. Palaeoecology 203: $277-297$

Biondi, D.; Leal, L.; Martini, A. \& Natal, C.M. 2009. Caracterização dendrométrica de Dicksonia sellowiana Hook. em povoamento de Araucaria angustifolia (Bertol.) Kuntze. Cerne 15(4): 453-459.

Bittencourt, S.; Corte, A.P.D. \& Sanquetta. C.R. 2004. Estrutura da comunidade de pteridophyta em uma Floresta Ombrófila Mista, Sul do Paraná, Brasil. Silva Lusitana 12: 243-254.

Burnham, K.P. \& Anderson, D.R. 2002. Model selection and multimodel inference: a practical information-theoretic approach. 2nd. New York, Springer-Verlag.

CIENTEC - Consultoria e Desenvolvimento de Sistemas Ltda. 2002. Mata Nativa - Sistema para análise fitossociológica e elaboração de planos de manejo de florestas nativas. São Paulo.

CONAMA. Conselho Nacional do Meio Ambiente (Brasil). 1994. Resolução CONAMA 04/94, de 4 de maio de 1994. Diário Oficial da União de 17 de junho de 1994, nº 114. Seção 1. Pp. 8877-8878

Connell, J. H. \& Lowman, M. D. 1989. Low-diversity tropical rain forests: some possible mechanisms for their existence. American Naturalist 134: $88-11$

Cortez, L. 2001. Pteridofitas epifitas encontradas en Cyatheaceae y Dicksoniaceae de los bosques nublados de Venezuela. Gayana Botánica 58: $13-23$.

Diniz-Filho, J.A.F., Bini, L.M. \& Hawkins, B.A. 2003. Spatial autocorrelation and red herrings in geographical ecology. Global Ecology and Biogeography 12(1): 53-64.

Dittrich, V.A.O.; Waechter, J.L. \& Salino. A. 2005. Species richness of pteridophytes in a montane Atlantic rain forest plot of Southern Brazil. Acta Botanica Brasilica 19: 519-525.

Epagri. 2008. Atlas climatológico do Estado de Santa Catarina. Disponível em <http://ciram.epagri.rct-sc.br>. (Acesso em 20/09/2008)

Fernandes, I. 1997. Taxonomia e Fitogeografia de Cyatheaceae e Dicksoniaceae nas Regióes Sul e Sudeste do Brasil. Tese de Doutorado. Universidade de São Paulo, São Paulo.

Fernandes, I. 2000. Taxonomia dos representantes de Dicksoniaceae no Brasil. Pesquisas, Botânica 50: 5-26.

Fortin, M.J. \& Dale, M.R.T. 2005. Spatial analysis: a guide for ecologists. Cambridge, Cambridge University Press.

Fraga, L.L.; Silva, L.B. da \& Schmitt, J.L. 2008, Composição e distribuição vertical de pteridófitas epifíticas sobre Dicksonia sellowiana Hook. (Dicksoniaceae), em floresta ombrófila mista no Sul do Brasil. Biota Neotropica 8: 123-129.

Franz, I. \& Schmitt, J.L. 2005. Blechnum brasiliense Desv. (Pteridophyta, Blechnaceae): estrutura populacional e desenvolvimento da fase esporofítica. Pesquisas, Botânica 56: 173-184.

Gomes, J.F.; Longhi, S.J.; Araújo, M.M. \& Brena, D.A. 2008. Classificação e crescimento de unidades de vegetação em Floresta Ombrófila Mista, São Francisco de Paula, RS. Ciência Florestal 18: 93-107.

Hart, T. B.; Hart, J. A. \& Murphy, P. G. 1989. Monodominant and speciesrich forests of the humid tropics: causes for their co-occurrence. American Naturalist 133: 613-633

Jones, M.M.; Tuomisto, H.; Clark, D.B. \& Olivas, P. 2006. Effects of mesoscale environmental heterogeneity and dispersal limitation on floristic variation in rain forest ferns. Journal of Ecology 94(1): 181-195.

Klein, R.M. 1978. Mapa fitogeográfico de Santa Catarina. Itajaí, Herbário Barbosa Rodrigues.

Legendre, P. \& Fortin, M.J. 1989. Spatial pattern and ecological analysis. Vegetatio 80(2): 107-138.

Lehn, C.R. \& Resende, U.M. 2007. Estrutura populacional e padrão de distribuição espacial de Cyathea delgadii Sternb.(Cyatheaceae) em uma Floresta Estacional Semidecidual no Brasil Central. Revista Biociências 13(3-4): 188-195.
Leite, P.F. \& Klein, R.M. 1990. Geografia do Brasil - Região Sul. Rio de Janeiro, IBGE

Maack, R. 1968. Geografia Física do Estado do Paraná. Instituto de Biologia e Pesquisa Tecnológica, UFPR.Curitiba, Instituto de Biologia e Pesquisa Tecnológica.

Mantovani, M. 2004. Caracterização de populações naturais de xaxim (Dicksonia sellowiana (Presl.) Hooker), em diferentes condições edafo-climáticas no estado de Santa Catarina. Dissertação de Mestrado. Universidade Federal de Santa Catarina, Florianópolis.

Margurran, A. 1988. Ecological Diversity and its Measurement. Princeton: Princeton University Press

MMA (Ministério do Meio Ambiente). 2008. Pp. 75-83. In: Lista oficial de espécies da flora brasileira ameaçada de extinção. Diário Oficial da União de 24 de setembro de 2008, n 185 . Seção 1.

Mueller-Dombois, D. \& Ellenberg, H. 1974. Aims and methods of vegetation ecology. New York, Wiley.

Nimer, E. 1989. Climatologia da região sul. In: Nimer, E. 1989. Climatologia do Brasil. 2 ed. Rio de Janeiro, IBGE/Dep. de Recursos Naturais e Estudos Ambientais.

Oliveira-Filho, A.T.; Curi, N.; Vilela, E.A. \& Carvalho, D.A. 1998. Effects of canopy gaps, topography and soils on the distribution of woody species in a central Brazilian deciduous dry forest. Biotropica 30(3): 362-375.

Page, C.N. 2002. Ecological strategies in fern evolution: a neopteridological overview. Review of Palaeobotany and Palynology 119(1-2): 1-33.

Pillar, V.D.; Müller, S.C.; Castilhos, Z. \& Jacques, A.V.A. 2009. Campos Sulinos: Conservação e Uso Sustentável da Biodiversidade. v. 1. Brasília, Ministério do Meio Ambiente.

Rangel, T.F.; Diniz-Filho, J.A.F. \& Bini, L.M. 2010 SAM: A comprehensive application for Spatial Analysis in Macroecology. Ecography 33: 1-5.

Rolim, L.B. \& Salino, A. 2008. Polypodiaceae Bercht \& J. Presl (Polypodiopsida) no Parque Estadual do Itacolomi, MG, Brasil. Lundiana 9: 83-106.

Salino, A. \& Almeida, T.E. 2008. Pteridófitas do Parque Estadual do Jacupiranga, SP, Brasil. Acta Botanica Brasilica 22(4): 983-991.

Sampaio, M.B. \& Guarino, E.S.G. 2007. Efeitos do pastoreio de bovinos na estrutura populacional de plantas em fragmentos de Floresta Ombrófila Mista. Revista Árvore 31: 1035-1046.

Sanquetta, C.R.; Côrte, A.P.D.; Salzmann, A.M. \& Vulcanis, L. 2007. Dinâmica de um remanescente de Floresta Ombrófila Mista no sul do Paraná sob influência de taquaras. Ambiência 3(1): 65-78.

Santa Catarina. 2007. Plano estadual de recursos hídricos de Santa Catarina-PERH/SC. Etapa A: Diagnóstico da situação atual dos recursos hídricos. Relatório Temático (RT - 05): Diagnóstico da dinâmica sócio-institucional das regiões hidrográficas. Florianópolis, Secretaria de Estado do Desenvolvimento Sustentável.

Santos, M.G. \& Sylvestre, L.S. 2006. Aspectos florísticos e econômicos das pteridófitas de um afloramento rochoso do Estado do Rio de Janeiro, Brasil. Acta Botanica Brasilica 20: 115-124.

SAR. Secretaria de Agricultura e Abastecimento do Estado de Santa Catarina. 2005. Inventário Florístico Florestal de Santa Catarina: Relatório do Projeto Piloto. Florianópolis, Mimeo.

Schmitt, J.L. \& Windisch, P.G. 2005. Aspectos ecológicos de Alsophila setosa Kaulf. (Cyatheaceae, Pteridophyta) no Rio Grande do Sul, Brasil. Acta Botanica Brasilica 19(4): 859-865.

Schmitt, J.L. \& Windisch, P.G. 2007. Estrutura populacional e desenvolvimento da fase esporofítica de Cyathea delgadii Sternb. (Cyatheaceae, Monilophyta) no sul do Brasil. Acta Botanica Brasilica 21(3): 731-740

Schmitt, J.L.; Schneider, P.H. \& Windisch, P.G. 2009. Crescimento do cáudice e fenologia de Dicksonia sellowiana Hook. (Dicksoniaceae) no sul do Brasil. Acta Botanica Brasilica 23(1): 283-291.

Seaby, R.M. \& Henderson, P.A. 2007. QED Statistics. Lymington, Pisces Conservation Ltd.

Sehnem, A. 1978. Ciateáceas. Flora Ilustrada Catarinense. Itajaí, Herbário Barbosa Rodrigues.

Senna, R.M. \& Kazmirczak, C. 1997. Pteridófitas de um remanescente florestal no morro da Extrema, Porto Alegre, RS. Revista da Faculdade de Zootecnia, Veterinária e Agronomia 4(1): 47-57 
Senna, R.M. 1996. Pteridófitas no interior de uma floresta com Araucária: composição florística e estrutura ecológica. Dissertação de Mestrado. Universidade Federal do Rio Grande do Sul, Porto Alegre.

StatSoft Inc. 2007. StatSoft, Statistica 8 Software. Tucksa, StatSoft.

Tryon, R.M. \& Tryon, A.F. 1982. Ferns and allied plants with special reference to Tropical America. New York Springer-Verlag.

Tuomisto, H. \& Poulsen, A.D. 2000. Pteridophyte diversity and species composition in four Amazonian rain forests. Journal of Vegetation Science 11: 383-396

Tuomisto, H.; Ruokolainen, K.; Poulsen, A.D.; Moran, R.C.; Quintana, C.; Canas, G. \& Celi, J. 2002. Distribution and diversity of pteridophytes and Melastomataceae along edaphic gradients in Yasuni National Park, Ecuadorian Amazonia. Biotropica 34(4): 516-533.
Veloso, H.P.; Rangel Filho, A.L.R. \& Lima, J.C.A. 1991. Classificação da vegetação brasileira, adaptada a um sistema universal. Rio de Janeiro, IBGE.

Vibrans, A.C.; Sevegnani, L.; Lingner, D.V.; Gasper, A.L. \& Sabbagh, S. 2010. Inventário florístico florestal de Santa Catarina (IFFSC): aspectos metodológicos e operacionais. Pesquisa Florestal Brasileira 30(64): 291-302.

Windisch, P.G. 2002. Pteridófitas do Brasil: diversidade decrescente. Pp. 196-198. In: Araujo, E.L.; Moura, A.N.; Sampaio, E.V.S.B.; Gestinari, L.M.S. \& Carneiro, J.M.T. (Eds.). Biodiversidade, conservação e uso sustentável da flora do Brasil. Recife, Universidade Federal Rural de Pernambuco e Sociedade Botânica do Brasil. 